\title{
Student reflections of psychiatric/mental health: Using journals and creative expressions
}

\author{
Melinda Hermanns , Barbara Haas \\ School of Nursing, The University of Texas at Tyler, Tyler, Texas, United States
}

Received: November 30, 2015

Accepted: February 29, $2016 \quad$ Online Published: March 30, 2016

DOI: $10.5430 /$ jnep.v6n8p69

URL: http://dx.doi.org/10.5430/jnep.v6n8p69

\begin{abstract}
Second semester undergraduate nursing students in their psychiatric/mental health clinical rotation express an array of emotions as they frequently view the setting as foreign. Two assignments, reflective journaling and a form of expression were incorporated into clinical to provide students an opportunity to reflect and convey their thoughts and feelings concerning their clinical experiences. Thematic analysis was used to analyze 10 journals and 10 art forms with a written description. Two content themes emerged: A Change in Perspective and Insight. Exemplars of the students' perspectives are provided. As evidenced by students' submissions, reflective journaling and creative expression can be an effective and beneficial assignment for students grappling with the complexities of psychiatric/mental health nursing.
\end{abstract}

Key Words: Psychiatric/mental health, Baccalaureate nursing students, Journaling

\section{INTRODUCTION}

Psychiatric/mental health nursing is one of the core courses for undergraduate nursing students, but the complex and abstract nature of much of the content makes it a challenge for many students. However, the need for nurses who are wellversed in sound mental health principles continues to grow. While approximately 1 in 10 persons worldwide suffers from a mental disorder, only $1 \%$ of health care professionals work in the psychiatric/mental health field. The global action plan developed by the World Health Organization (WHO) Mental Health Atlas (2015) outlined specific objectives to address the availability of services and resources in mental health. ${ }^{[1]}$ The prevalence of mental health issues is on the rise, and this increase necessitates the need for trained health care providers who can provide holistic care for this specialized population.

\subsection{Background}

Psychiatric/mental health content usually is placed in second or third semester nursing school. The purpose of this article is to describe a strategy used to help nursing students overcome their initial hesitation to engage with the mentally ill in various clinical facilities during their clinical experiences. Using the principles of human caring as a basic philosophy, faculty devised an activity that would facilitate the transition from caring for a patient with medical-surgical needs to caring for the mentally ill. This process began by examining Peplau's foundational work in the nurse-patient relationship. ${ }^{[2]}$ This approach supports the basic underpinning of nursing as espoused by Florence Nightingale who proposed treating the whole person as a physiological, psychological, sociological, and spiritual being. ${ }^{[3]}$ The philosophies of these two nursing pioneers have significantly impacted the nursing profession through promoting the importance of patient-centered care

\footnotetext{
*Correspondence: Melinda Hermanns; Email: mhermanns@uttyler.edu; Address: The University of Texas at Tyler, School of Nursing, 3900 University Blvd, Tyler, Texas 75799, United States.
} 
and addressing the body, mind, and spirit. Nurses employ both the humanistic art and scientific process in the delivery of care on a day-to-day basis. As nursing faculty we are obligated to help students learn how to holistically care for patients who are vulnerable, such as those with mental illness. To facilitate the incorporation of holistic care, the following questions were posed: (1) how can faculty help students become more familiar with the principles guiding care for persons with mental illness? and (2) what can faculty do to help change students' perceptions of caring for the mentally ill?

\subsection{Challenges students experience in psychiatric/men- tal health nursing}

Conveying the complexity of psychiatric/mental health nursing is a challenge for educators of undergraduate student nurses. The goal is to encourage students to understand both the science of psychiatric/mental health nursing and the art of caring for persons with a mental illness. For many, the concept of psychiatric mental health is abstract and difficult to understand. Many students share that even after reading the psychiatric mental health textbook, attending classes, and visiting inpatient psychiatric facilities, understanding how to apply principles is difficult. Clinical experiences provide limited exposure to psychiatric mental health disorders and chronic mental health conditions. When students enter the clinical setting, many view the experience as foreign and/or mysterious. In an attempt to further understand the concepts of psychiatric mental health and facilitate the transition from class to clinical, students are taught the science of psychiatric/mental health in the didactic portion of the course. It is in the clinical setting where the classroom becomes 'real' when the students can actually see what they have learned In this course, we subscribe to an active pedagogy as there is not a one-step approach to teaching. We incorporated a variety of teaching strategies, i.e., simulations/case studies and other active learning strategies to engage our students in integrating the clinical and the classroom experience. "If you see something in clinical and then study it in class, or study it in class and see it in clinical... it's just burned into your brain-what's going on, what's happening-and you never forget it". ${ }^{[4]}$

\subsection{Reflective journaling}

Student journaling is an accepted way to expand the depth and richness of the clinical experience to promote critical thinking in undergraduate students. The National League for Nursing has identified the promotion of both reflective and critical thinking as important core competencies of nurse educators to use in facilitating students' learning. ${ }^{[5]}$ One means to meet these core competencies is through the use of reflective journaling. Sigma Theta Tau International Honor Society (2014) has released a position paper on the scholarship of reflective practice. ${ }^{[6]}$ Global initiatives are being recommended for the use of reflective practice as well.

The use of reflective journals to promote reflective and critical thinking is not without controversy. ${ }^{[7]}$ Consensus among many nurse educators is that reflective journaling is valuable and beneficial to the students' learning process; further, many educators believe journaling may promote reflective and critical thinking. ${ }^{[8,9]}$ However, much consideration is needed when faculty are contemplating implementing a journaling assignment, including identifying the purpose, conveying the expectations (graded, non-graded), and the type of journal format to be used (i.e., structured verses guided format). Evidence supports that guided reflection helps students to actively engage in soul-searching to describe a deeper description rather than superficially describing an experience. ${ }^{[10,11]}$

\subsection{Description of strategic innovation}

Based on collective faculty expertise in mental health, a strategic intervention was developed to help students interpret their experiences with patients with mental illness in terms they could understand and incorporate into their nursing skillset. The intervention was designed to expand the depth of the post-clinical sessions by encouraging student reflection on what had transpired during their clinical day. Historically, debriefings were a traditional part of the inpatient experience usually held in a post-clinical conference setting. However, we observed the depth of feelings and emotions may not be fully realized by the student and/or fully conveyed at the time the debriefing sessions are held. Therefore, a reflective journaling requirement including both a written journal reflection and a creative therapeutic form of expression was implemented.

In our course faculty chose to develop a reflective journaling template that is similar to a guided reflection. Students were given a template for journaling that teaches them the value of documenting their experiences. Given the fact that students in psychiatric/mental health frequently experience an array of emotions on any given clinical day, a template is seen as a way to provide the student with direction, while at the same time having a broader focus. The journal template was developed with the intention that students would feel comfortable sharing their thoughts and feelings related to a specific clinical experience. Student input was requested regarding the format of the journal as we were and continue to be interested in understanding experiences through the students' perspective.

Furthermore, instructions were developed for students to in- 
clude a form of artistic expression to accompany their reflective journal, to further illustrate their thoughts and feelings. The therapeutic form of expression is an original creation; in the form of art, poetry, music, collages, and/or photographs. This type of therapeutic expression is a non-verbal form of expression created by the student to help express personal thoughts and feelings about the clinical experience and/or individual introspection. It further expands the students' written journal reflections. Since a template was provided for the reflective journaling, less constrictive measures were placed on the therapeutic form of expression in an effort to encourage creativity and free expression. Students were instructed to also provide a narrative description to accompany the creative form of expression. In this manuscript, we will share the students' meaningful thoughts, feelings, and reflections as noted in their reflective journaling and therapeutic form of expression.

\section{METHODS AND ANALYSIS}

All students enrolled in a junior level mental health course over the course of one academic year completed the reflective journal incorporating therapeutic forms of expression. Of the 40 students enrolled in the course, 20 granted permission for their journals to be used for this Institutional Review Board approved study. At the end of each semester, all journals and creative expression were collected and filed. The twenty (20) journals and twenty (20) therapeutic forms of expression received from consenting participants were stored in a separate file for analysis. Student identifiers were removed to ensure confidentiality.

Thematic analysis was used to identify themes. All journals and therapeutic forms of expression were read line-by-line by the primary researcher and comments were written in the margins of the journals. The journals and therapeutic forms of expression were re-read by the researcher and patterns and themes were identified from the descriptive journal content. When similar topics were identified, the text was highlighted and the topic was written in the right hand margin of the journal. All patterns and themes emerged from the data. The patterns and themes were then noted in a Word document along with supporting quotations for an audit trail. Saturation was reached following review of 10 reflective journals and 10 therapeutic forms of expression. At this point, high redundancy of findings indicated saturation. The process of coding involved separating the data into groups. Next, categories to facilitate insight and comparison were identified. ${ }^{[1]} \mathrm{Fi}-$ nally, codes were used to organize the text to allow for rapid retrieval and clustering of the theme. ${ }^{[12]}$ All data were hand coded and interrater agreement among two faculty reached a consistency of $100 \%$. We found deep, rich feelings, thoughts,

Published by Sciedu Press and emotions embedded in the various journal discussion which were supported by the art forms that students created days and even weeks following their clinical experience. Exemplars of the students' creative artistic forms to depict psychiatric mental health nursing as provided. Authenticity of the students' reflections was maintained through the use of student quotes.

\section{RESUlts}

Two themes, "A Change in Perspective" and "Insight" emerged from the journals and art forms. Each of these themes was supported by the students' words and creative expressions which are reflected in the following discussion of results.

\section{A Change in Perspective}

The students shared their thoughts, feelings, and perceptions regarding their clinical experience in their reflective journals. One of the most commonly occurring themes was "A Change in Perspective". Perspective is defined as "a particular attitude toward or a way of regarding something; a point of view". ${ }^{[13]}$ Many of the students had no previous experience with psychiatric/mental health and did not have a firm understanding of the principles underpinning the pathology, nor had they communicated with a person with a mental illness. This was a foreign experience for many who reflected confusion or guilt about their initial reaction of being a fearful and having a negative world view of psychiatric/mental health.

A majority of the students expressed feelings of empathy for patients when others have a world view which categorizes or stigmatizes individuals with mental illness. Supporting a change in perspective toward understanding and acceptance was a reappearing theme in the journals as well as in their artistic forms of expression. This form of expression also documents an account of the world view. The student eloquently and passionately stated, "Take that second glance. Change your perspective. There is beauty and purpose in everyone, if you just take the time to look." The lack of knowledge regarding psychiatric mental health, coupled with the stigmatization may attribute to such negative judgment. However, in reviewing all of the journals and forms of expression, it is evident that their clinical experience challenged the students to change their perspectives. Similar sentiments were echoed in another student's journal:

This clinical experience has opened my eyes. It has challenged me to see patients differently - to not conform to the world's view. So many patients in mental health are stigmatized and this is so sad. I have learned to not be judgmental, to take the time to understand who they are and their psychiatric disorder and to change my per- 
spective. Prior to being in Psych, I would be too quick to judge/condemn others, but understanding psychiatric mental health has enabled to me change my perspective. Changing my perspective will definitely help care for my patients when I graduate and become a practicing nurse. For that, I am grateful.

\section{Insight}

Insight is defined as "the capacity to gain an accurate and deep intuitive understanding of a person or thing". ${ }^{[13]}$ In the debriefing sessions following the clinical experiences, students would begin to discuss and reflect on what it would be like to have a mental disorder, and what they can do as a nursing student to help the individual. This insight was also reflected in their journals and forms of expression.

It will definitely be hard [having a mental disorder], but I am sure that we can shed a little light in their confused and sad world.

Each day brings new challenges that cause them to move further away from what once were until they spiral out of control. I imagine this is what these individuals must feel like when they start to loose themselves to their disease and that is hard for things to stop spinning out of control without help.

To me, it was what the residents would want to do: to be able to live on, without worry or thought about the things they can't control, and the mood of this piece reflects that.

As nurses, we are the gardeners and should never disregard those who are withered, but treat them with dignity and provide them the same level of care as other patients.

\section{Discussion}

Reflective journaling is deemed to be a therapeutic and beneficial preparation ${ }^{[14]}$ for student nurses' acquisition of skills and future success as practicing professionals. This assertion is supported by the premise of Johns who proposed that if nurses become better able to practice the art of nursing in a reflective and holistic manner, they would be "attentive" to their patient's personal suffering. ${ }^{[15]}$ It is our belief that reflective journaling coupled with an art form (i.e., form of expression) may help foster development of holistic and caring student nurses who ultimately become professional and caring registered nurses. Just as students reflect on their experiences and gain a deeper understanding and appreciation of psychiatric/mental health, a caring nurse can assist patients to discover a new sense of self and personal awareness to accelerate individual growth and healing. ${ }^{[16]}$ It is possible that journaling and creative artistic expression may serve as an effective therapeutic modality.

Journaling may serve a dual purpose. In addition to allowing students to reflect on the application of principles of mental health caring to patients in the psychiatric setting, it may serve as a coping mechanism for students encountering patients with mental illness. Reflective journaling potentially has the power to provide students with skills to manage emotions in caring for patients in a variety of health care environments across the wellness continuum. One of the advantages of the artistic form of expression is that it became a venue for students to express thoughts, emotions, and feelings through a creative and individualistic way. Psychiatric mental health students were encouraged to utilize their creativity to express their thoughts, emotions, and feelings regarding the differences between mental health wellness and mental illness that they observed as they interacted with patients during their clinical experience. ${ }^{[11]}$

The reflective journaling with a creative artistic expression allowed each student to engage in reflective practice during their educational process where they have a protected and nurturing environment with feedback from mental health experts. While exemplars have been provided, all students in the study demonstrated a positive change in perspective in relation to caring for persons with mental illness. Given the rise in mental health issues around the nation, ${ }^{[17]}$ health care professionals with expertise and comfort in this area will be needed. Additionally, there is a continued need for holistic delivery of care as envisioned by Peplau and Nightingale. The innovative and creative educational strategy employed in this study appears to be one means to help nursing students see patients with mental health holistically, thereby decreasing their fear and discomfort with working in the stigmatized world of psychiatric/mental health.

\section{CONFlicts OF InTEREST Disclosure}

The authors declared no potential conflicts of interest with respect to the research, authorship and/or publication of this article. The project's funding source had no role in study design; in the collection, analysis and interpretation of data; in the writing of the report; or in the decision to submit the paper for publication.

\section{REFERENCES}

[1] World Health Organization. Mental health atlas 2014. Geneva Switzerland; 2015. http://www.who.int/mental_health/ev idence/atlas/mental_health_atlas_2014/en/

[2] American Nurses Association. Hildegard Peplau (1909-1999) 1998 inductee. 2015. Available from: http://www.nursingworld.org 
/HildegardPeplau

[3] Nightingale F. Notes on Nursing What It Is, and What It Is Not. New York, NY: D Appleton \& Company; 1860.

[4] Benner P, Sutphe M, Leonard V, et al. Educating nurses: A call for radical transformation (p. 127). San Francisco: Jossey-Bass; 2010.

[5] Halstead JA. Nurse educator competencies: Creating an evidencebased practice for nurse educators. New York: National League for Nursing; 2007.

[6] Sigma Theta Tau International. The scholarship of reflective practice. Position paper; 2014. Available from: https://www.nursingsociety.org/docs/default-source/ position-papers/resource_reflective.pdf?sfvrsn=4

[7] Boud D. Using journal writing to enhance reflective practice. New Directions for Adult and Continuing Education. 2001; 90.

[8] Carlson SC. Instructional methods influence critical thinking: Do students and instructors agree? Academy of Educational Leadership Journal. 2013; 17(1): 27-32.

[9] Crenshaw P, Hale E, Harper SL. Producing intellectual labor in the classroom: The utilization of a critical thinking model to help students take command of their thinking. Journal of College Teaching \& Learning. 2011; 8(7): 13-26.
[10] Nickel J. Formative assessment and syntheses in reflection journals. Transformative Dialogues: Teaching \& Learning Journal. 2012; 6(3): $1-16$.

[11] Holt-Waldo N, Stanley-Hermanns M. Journaling unlocks fears in clinical practice. RN. 2009; 72(5): 26-31.

[12] Miles MB. Qualitative data analysis: A methods sourcebook. Thousand Oaks, CA: Sage Publications; 2014.

[13] Lindberg CA, Stevenson A. (Eds.). New Oxford American dictionary (3rd ed.). Oxford: Oxford University Press; 2010, p. 899; 1308.

[14] Hendrix TJ, O'Malley M, Sullivan C, et al. Nursing student perceptions of reflective journaling: A conjoint value analysis. Int Scholarly Res Network. 2012. Article 317372. Available from: http://www.hindawi.com/journals/isrn/2012/317372/

[15] Johns C. The value of reflective practice for nursing. Journal of Clinical Nursing. 1995; 4(1): 23-30. http://dx.doi.org/10.1111/j .1365-2702.1995.tb00006.x

[16] Newman MA. Transforming presence: The difference that nursing makes. Philadelphia: F. A. Davis Company; 2008.

[17] Center for Disease Control and Prevention. Health, United States, 2014 - Mental Health; 2015. Available from: http://www. cdc.go v/nchs/data/hus/2014/021.pdf 